\title{
PERFORMANCE EVALUATION OF SLAG AND CRUCIBLE DISSOLVER
}

DEVIELPPIEAT

and

REPORT

J. Dunn

RELEASED FOR ANNOUNCEMENT

IN NUCLEAR SCIENCE ABSTRACTS

July, 1965

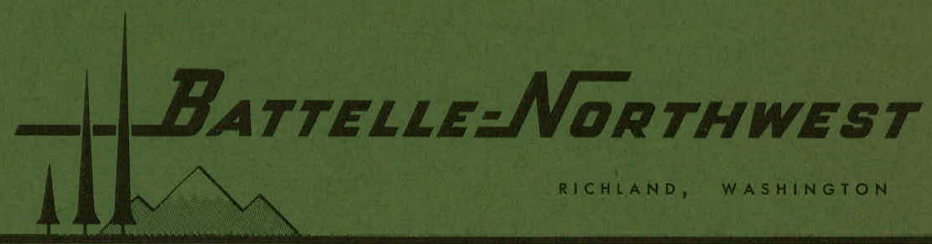

PACIFIC NORTHWEST LABORATORY operated by BATTELLE MEMORIAL INSTITUTE 


\section{DISCLAIMER}

This report was prepared as an account of work sponsored by an agency of the United States Government. Neither the United States Government nor any agency Thereof, nor any of their employees, makes any warranty, express or implied, or assumes any legal liability or responsibility for the accuracy, completeness, or usefulness of any information, apparatus, product, or process disclosed, or represents that its use would not infringe privately owned rights. Reference herein to any specific commercial product, process, or service by trade name, trademark, manufacturer, or otherwise does not necessarily constitute or imply its endorsement, recommendation, or favoring by the United States Government or any agency thereof. The views and opinions of authors expressed herein do not necessarily state or reflect those of the United States Government or any agency thereof. 


\section{DISCLAIMER}

Portions of this document may be illegible in electronic image products. Images are produced from the best available original document. 


\section{LEGAL NOTICE}

This report was prepared as an account of Government sponsored work. Neither the United States, nor the Commission, nor any person acting on behalf of the Commission:

A. Makes any warranty or representation, expressed or implied, with respect to the accuracy, completeness, or usefulness of the information contained in this report, or that the use of any information, apparatus, method, or process disclosed in this report may not infringe privately owned rights; or

B. Assumes any liabilities with respect to the use of, or for damages resulting from the use of any information, apparatus, method, or process disclosed in this report.

As used in the above, "person acting on behalf of the Commission" includes any employee or contractor of the Commission, or employee of such contractor, to the extent that such employee or contractor of the Commission, or employee of such contractor prepares, disseminates, or provides access to, any information pursuant to his employment or contract with the Commission, or his employment with such contractor.

\section{PACIFIC NORTHWEST LABORATORY \\ RICHLAND, WASHINGTON \\ operated by \\ BATTELLE MEMORIAL INSTITUTE}

for the

UNITED STATES ATOMIC ENERGY COMMISSION UNDER CONTRACT AT(45-1)-1830 
BNWL-121

UC-38; Engineering and Equipment

PERFORMANCE - EVALUATION OF-SLAG AND CRUCIBLE DISSOLVER

By

J. Dinn

Chemical Development Section

Chemistry Department

July, 1965

PACIFIC NORTHWEST LABORATORY

RICHLAND, WASHINGTON 


\section{PERFORMANCE EVALUATION 'OF' SEAG AND CRUCIBLE DISSOLVER}

by

J. Dunn

\section{INTRODUCTION}

Development and testing of continuous dissolvers for processing slag and crucible residues obtained in the production of plutoniam metal have been described in previous reports ${ }^{1,2,3}$. During the latter part of 1964 , performance testing of a prototype dissolver"for the Plutonium"Reclamation Facility was completed. Because of the immediate needs for this unit in the plant; there was not time: to investigate some design improvements conceived during the prototype test. Subsequently; additional studies were performed using a glass mock-up of an improved design. This report describes the recent design modifications and the results of tests made to determine the resulting performance characteristics.

\section{SUMMARY}

A glass mock-up of the liquid portion of a continuous dissolver has been satisfactorily operated under stringent process conditions" Dissolution of simulated slag and crucible residues was accomplished at rates two to three times greater than present plant production-rates. The ability of the system to maintain or restore circulation, whlle containing solids equivalent to the insoluble material resulting from about six montis' normal production, has been demonstrated. The addition of metered steam through sparge-distributors to obtain required dilution of the production provides agitation; reduces feed storage requirements and simplifies feed make-up. 


\section{DESCRIPTION : OF' PROCESS" EQUIPMENT}

During the reduction and purification of platonium; some "of the metal. is carried into slag and is deposited on or in the crucibles used in the column reduction process. In order to recover this metal the residues arế ground and blended in powder form: The powder is sealed in iron cans which are capable of belis "totaliy dissolved by a wet chemical process for reclaw mation of the metal. The dissolution of the basic residues is accomplished rapidly by a hot mixture of nitric acid and aluminum nitrate which in the presence of soluble fluorides: leaves only minor amounts of insoluble salts such as magnesium stilcate. Development of a dissolver which circulates the heated acidic mixture with the"solids in a turbulent flow is described in earlier reports $1,2,3$.

The dissolver illustrated" in Figure 1 operates on the same principle as that described in the references;"it differs in luat provisions are made for access from adjacent hoods::0ther minor improvements have been included to reduce solids holdup and to provide cleaner product streams and to insure more complete dissolution.." The design incorporates a closed loop for containing acidic"solvent. The solvent"is"circulated in the loop by means of a thermal"siphon supplemented with" an inert gas air-lift。 The inert gas serves a multiple function - generating the lifting effect, providing a blanket in the equipment to reduce" or eliminate explosive mixtures of the evolved hydrogen, and serving to agitate and suspend solids in the acid。 The parallel addition of live steam through the sparge lines provides agitation of the solids; dilutes the solution and provides supplementary heat to the process. 
The rising liquid circulates around and through the canned residues as they are deposited in the vertical-section of the dissolver, continues horizontalily to promote both dissolution and disengagement of the inert gas and returns to the lower section of the equipment for redistribution. The down- comer is:sloped to provide gravity assistance to the circulation of the solids。 At the bottom of the sloped"section, where connection is made to the vertical portion, a horizontal run of pipe has been provided to extend through the canyon wall into a closed hood in an adjacent room. The dissolver can be mechanically scraped through this pipe to remove sollds without physically entering the canyon. Fresh solvent addition and introduction of purge gas and sparge steam are also made through this same horizontal pipe during normal operation. These additions serve to stir any deposited solids and to speed up dissolution.

A horizontal plpe located noar the top of the alssolver connects the two vertical portions and serves to carry off gas and vapors. It also acts as a surge chamber and prevents the mechanical sweep of liquid and solids into the condenser. The product solution take-off, a constant overflow arrangement, has been relocated to the top side of the sloped downcomer in a region of relatively low turbulence. Screens in the liquid and vapor cross-over lines and in the vertical heated section prevent the loss of displacement of large pieces of undissolved material and retain them in the actively boiling section while disintegration takes place.

Since this series of tests was concerned with process variants and minor untested items of the basic design, no attempt was made to prototype the entire dissolver. The model was fabricated from available Pyrex glass pipe where possible to allow visual observation of the action. Flgure 2 is a diagram of the test dissolver. 
TEST OPERATION

Several charges of simulated feed; without calcium metal, plutonium or the iron from the steel can were dissolved in the equipment to verify circulation and dissolution and to provide data for sparge distributor design. These runs were of short duration because of the extensive modifications that would have been required to safely perform the task on a continuing hasis. The dissolver was filled to the overflow point with a mixture of 10M nitric acid and $0.25 \mathrm{M}$ aluminum nitrate (ANN)。 The inert gas sparge was started using air as a standin for nftrogen and steam was applied to the heat exchanger. When the solution temperature was raised to about $85 \mathrm{C}$ approximately 1500 grams of a simulated feed of magnesium oxide, calcium fluoride and calcium or alternatively potassium iodide were charged as a dry powder. The acid flow was continuous and at a rate of 17 liters per "can" of solid feed. This represents a large excess of acid over the stoichiometric 7 liters required, but provides more positive driving force for the dissolution. During the dissolving cycle the temperature of the solution rises rapidly and attains approximately 95 Co Circulation was maintained by the inert gas and thermal syphon. A fresh "can" of residues was added at 30 minute intervals until eight charges had been made. The solids settling on the bottom of the down comer were agitated and put back into the circulating stream by operation of the steam sparge。

In a second test the concentrations were changed to provide $12.5 \mathrm{M}$ nitric acid and $0.3 \mathrm{M} A N N$. During the dissolution of elght cans of residues the steam sparge was operated continuously for 10 minutes per can; steam was metered through an orifice to provide a measured dilution of the more concentrated acid mixture. Approximately five minutes after the addition of the eighth 
can the reaction rate suddenly accelerated and acid was splashed from the top of the model. The unit was shut down and an estimate of the undissolved solids was made. Less than one liter of solids was detected, Operation was resumed with the original acid concentration (10M)"but with slightly higher ANN $(0.3 \mathrm{M})$ to evaluate the effect on solubility of the granular fluoride residue. The next 4 cans were charged at a doutled rate - one every 15 minutes. Following an overnight shutdown the solids volume was apparently unchanged and charging of the solid material was resumed. After the second additional can had been charged (total of: 6) the reaction rate again spontaneously accelerated after about five minutes, and acid again spewed from the top of the dissolver. This increased secondary reaction pressure, which is easily contained in full scale plant equipment, has been repeatedly observed during production runs.

In the tests to determine ability of the dissolver to maintain or restore circulation of the solids after periods of shutdown, wind-blown desert sand was charged to the dissolver in increments of 1 liter. Water was substituted for the acidic solvent: When the sand had"been evenly distributed throughout the system the heat and sparges were turned off and the unit was allowed to stand overnight。 The resumption of heating and sparging generally restored circulation almost immediately unt1l 20 liters of sand had been added. From this point the circulation was more and more slowly restored。 The twentymeighth can required almost 10 minutes of operation before complete circulation was noted. After the 29 th liter of sand had been added and the system allowed to settle for 24 hours, it was impossible to restore circulation. However, it was observed that the sparge distributor had physically 
pulled away from the end of the air line and the sparge air was no longer emerging in the desired location. At this time it was estimated that the top or vapor cross-over line contained about two liters of deposited sand; the liquid cross-over held about six liters and the remainder was in the bottom horizontal section and in the vertical part of the dissolver.

\section{RESULTS}

The ability of the system to accommodate 29 liters of solids (equivalent to the insoluble residue from 2900 cans of slag and crucible residues) is felt to be considerably in excess of any foreseeable requirements. Additional improvement in the operation of the dissolver is foreseen in proposed changes by personnel of Plutonium Processing Engineering. The suggested addition of $12.5 \mathrm{M}$ nitric acid, $0: 3 \mathrm{M}$ ANN at the top of the dissolver and addition of $1 \mathrm{M}$ nitric acid, 2.5M ANN through the clean-out and sparge pipe will reduce or even eliminate the need for performing manual cleaning and solids removal by preventing the formation of insoluble materials. The required final product composition can be obtained by adjustment of these two flows and by the use of the dilution of the sparge steam. These points remain to be demonstrated; but because of the time and expense of completely prototyping the "0-8" dissolver in glass that is safe to operate in a coldsemiworks test stand it has been decided that they be proven during preliminary shakedown runs of the production dissolver.

Future development work will be primarily concerned with the section of better materials of construction and simplification of the components.

\section{ASSISTANCE}

Special acknowledgment is given to R。 J。 Sloat, L。 E。 Bruns, and C。A。 Lorenzen - CPD, General Electric, for timely assistance and suggestions during the development and testing work. 


\section{REFERENCES}

1. HoT。Blaine, Continuous Slag and Crucible Dissolver, "HW-68630。 General Electric Company; Richland; February, 196l。

2. HoWo Crocker Continuous-Dissolution of Plutonium-Bearing Slag and Crucible Residues, HW-69415: General Electric Company, Richland, June, 1961.

3. Jo Dunn。 Development of Plastic Lined Slag and Crucible Dissolver, BNWC-11, January, 1965." 


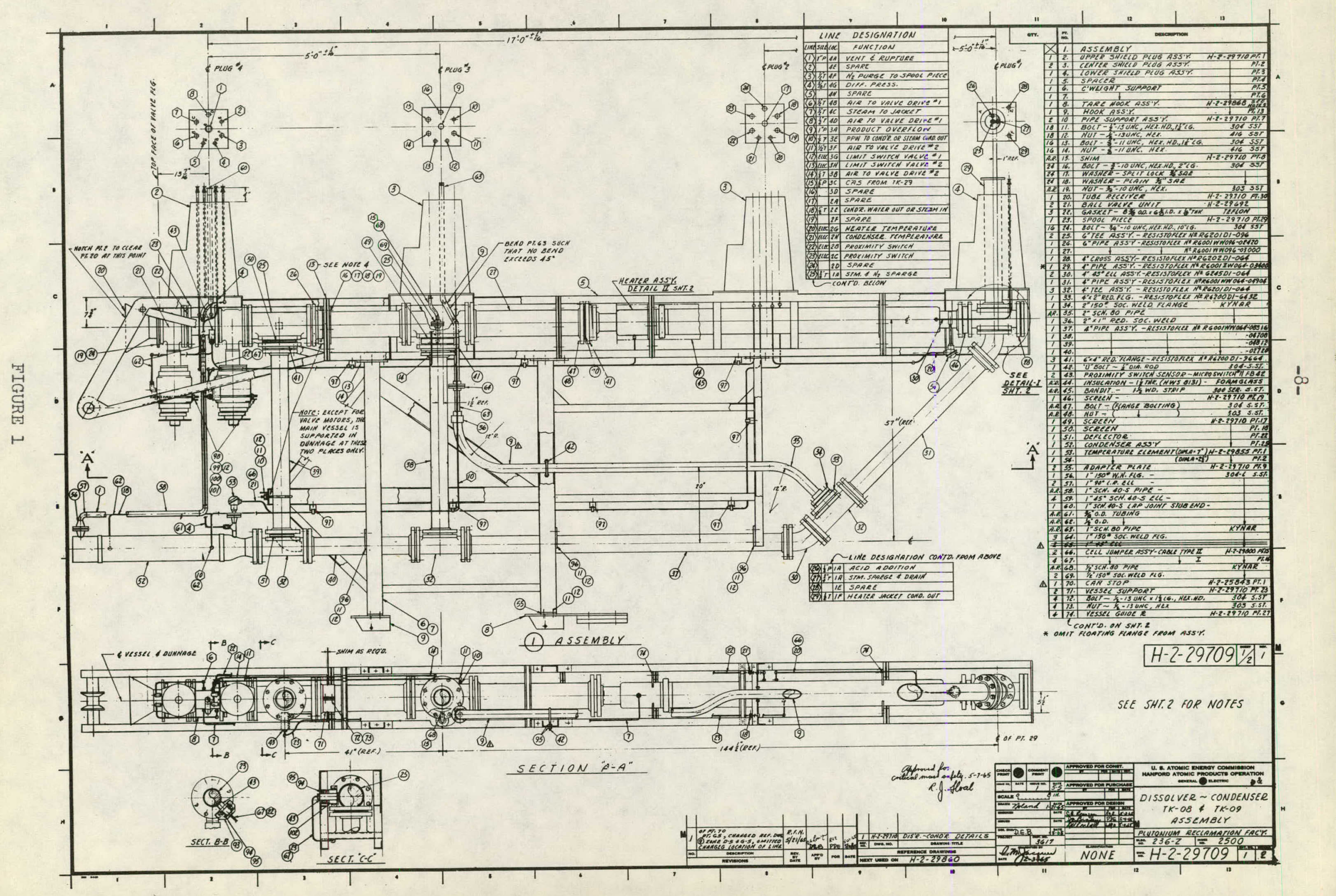




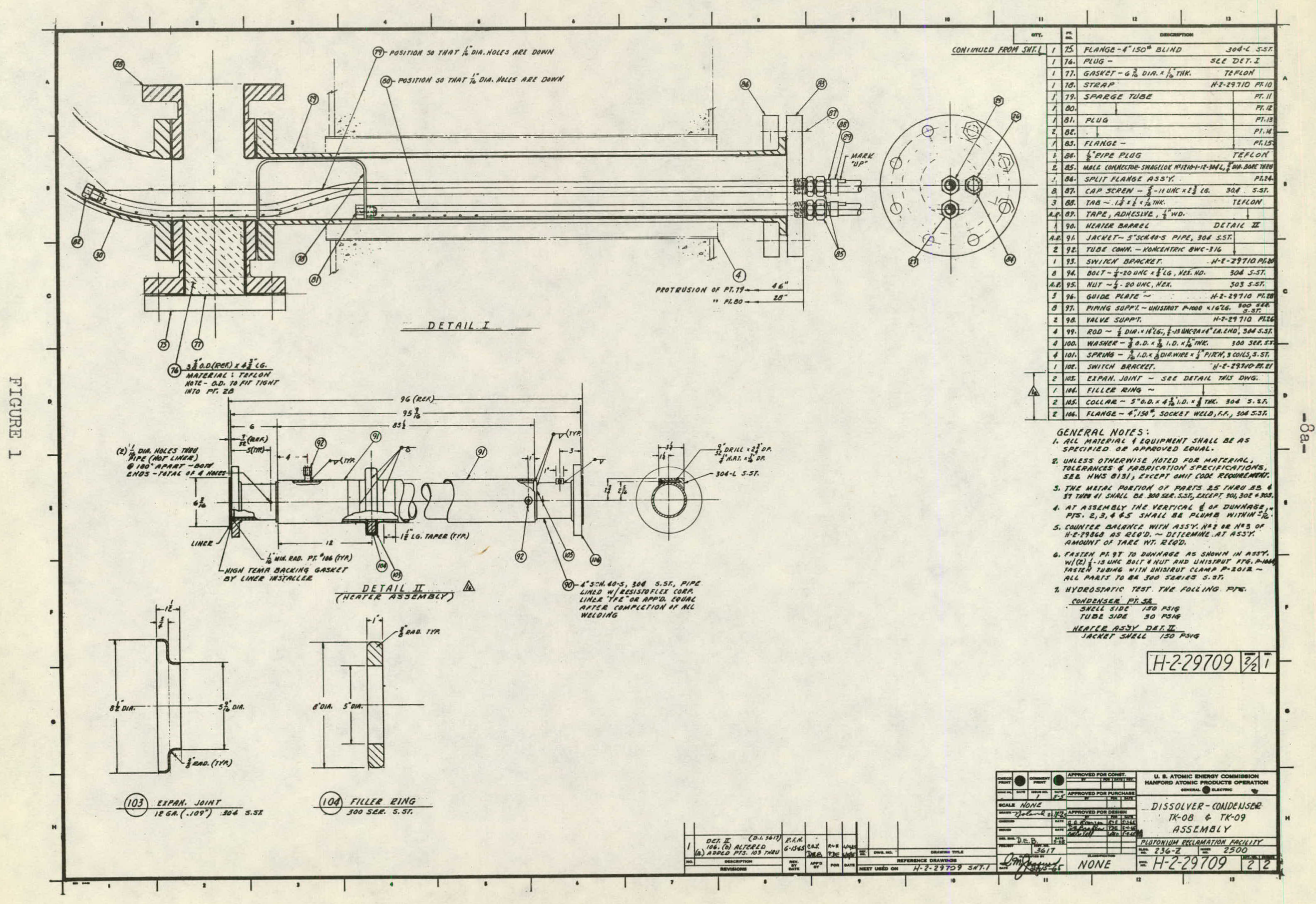


3

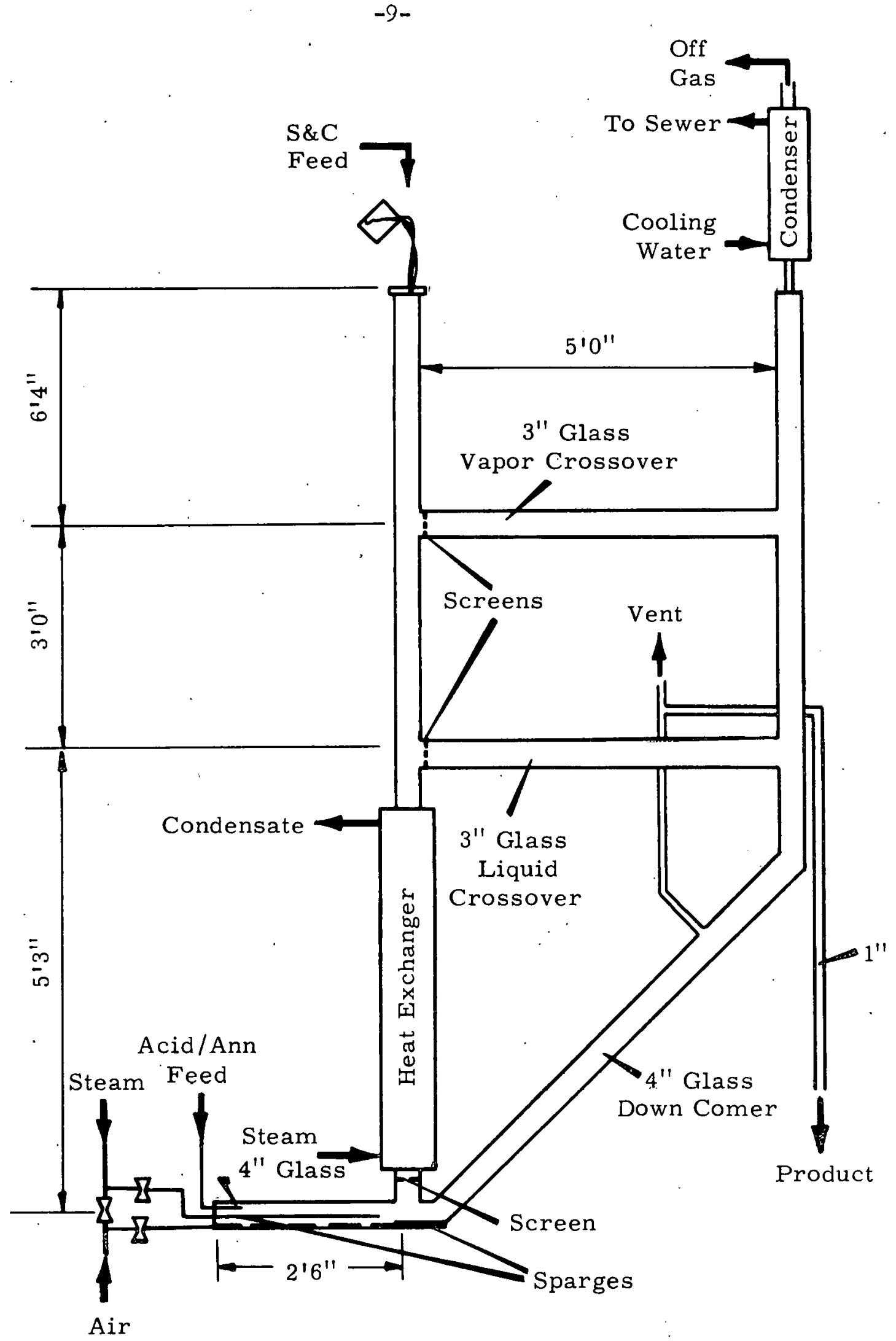

FIGURE 2 
ONSITE DISTRIBUTION

Copy Number

Pacific Northwest Laboratory

1

2

3

$4-9$

10

11

12

$13-15$
J。 Mo Atwood

$R_{0}$ E. Burns

C. R。 Cooley

$J$ 。 Dunn

A。 Mo Platt

W. Ho Swift

$M$ 。 $T$ 。 Walling

Central Files

General Electric-Company, Richland

16

17

18

19

20

21

22

23

24

25

26

27

28

29

30

31

32

33

34

35

36

37

38

\section{J。 Berglund}

L。A。Berry

D。 E。 Braden

L。 C。Brown

L。 E. Bruns

D。 $W_{0}$ Corbell

$\therefore$ D。 To Crawley

D。 Mo Creighton

J。 W。 Fillmore

S. G。 Smolen

C。 C. Hinson

$\mathrm{H}$ 。 $\mathrm{H}$ 。 Hopkins

W. $Y_{0}$ Ingalls

R. S。 Kingsley

L。 M。 Knights

C. A。 Lorenzen

A. J。 Low

C。 $W_{0}$ Nilsen

$R_{0} J_{0}$ Sloat

$M_{0} \cdot J_{0}$ Szulinski

$R_{0}$ E。 Tomlinson

$R_{0} L$ 。Walser

$\mathrm{V}$ 。 R。Weil

\section{Richland Operations Office}

39

R。K。 Sharp

OFFSITE DISTRIBUTION

No. of Copies

Division of Technical Information Extension 